\title{
Discovery of 3-Amino-2-Hydroxypropoxyisoflavone Derivatives as Potential Anti-HCV Agents
}

\author{
Jin-Ching Lee ${ }^{1}$, Chun-Kuang Lin ${ }^{1}$, Chin-Kai Tseng ${ }^{1}$, Yeh-Long Chen ${ }^{2}$, Cherng-Chyi Tzeng ${ }^{2}$ \\ and Chih-Hua Tseng $3,4,5,6, * \mathbb{D}$ \\ 1 Department of Biomedical Science and Environmental Biology, College of Life Science, \\ Kaohsiung Medical University, Kaohsiung City 807, Taiwan; jclee@kmu.edu.tw (J.-C.L.); \\ crystalsoul35@gmail.com (C.-K.L.); jimmytseng@biosidsco.com (C.-K.T.) \\ 2 Department of Medicinal and Applied Chemistry, College of Life Science, Kaohsiung Medical University, \\ Kaohsiung City 807, Taiwan; yeloch@kmu.edu.tw (Y.-L.C.); tzengch@kmu.edu.tw (C.-C.T.) \\ 3 School of Pharmacy, College of Pharmacy, Kaohsiung Medical University, Kaohsiung City 807, Taiwan \\ 4 Department of Fragrance and Cosmetic Science, College of Pharmacy, Kaohsiung Medical University, \\ Kaohsiung City 807, Taiwan \\ 5 Center for Infectious Disease and Cancer Research, Kaohsiung Medical University, \\ Kaohsiung City 807, Taiwan \\ 6 Department of Pharmacy, Kaohsiung Municipal Ta-Tung Hospital, Kaohsiung City 807, Taiwan \\ * Correspondence: chihhua@kmu.edu.tw
}

Received: 19 October 2018; Accepted: 31 October 2018; Published: 2 November 2018

\begin{abstract}
Synthesis and anti-hepatitis C virus (anti-HCV) effects of certain 3-amino-2hydroxy-propoxy isoflavone derivatives, 6a-i, were described. The known 3-(3,4-dimethoxyphenyl)- 7-(oxiran-2-ylmethoxy)-4H-chromen-4-one (5) was reacted with substituted amines to give the desired isoflavone derivatives, 6a-i. Among them, 7-\{3-[(3,4-dimethoxy-phenethyl)amino]-2-hydroxypropoxy\}-3-(3,4-dimethoxyphenyl)-4H-chromen4-one (6b) was the most active, exhibiting approximately 2-fold higher anti-HCV effects than standard antiviral drug ribavirin $\left(\mathrm{EC}_{50}\right.$ of $\left.6.53 \mathrm{vs} .13 .16 \mu \mathrm{M}\right)$. In addition, compound $\mathbf{6 b}$ was less cytotoxic than ribavirin. The selectivity index (SI) of $\mathbf{6 b}$ is approximately 2.6-fold higher than ribavirin. The compounds $\mathbf{6 e}, \mathbf{6 h}$, and $\mathbf{6} \mathbf{i}$ were also found to possess higher anti-HCV effects than ribavirin. Compound $\mathbf{6} \mathbf{b}$ was found to inhibit the HCV RNA expression in Ava5 cells in a dose-dependent manner; furthermore, we found that the antiviral mechanism of compounds $\mathbf{6 b}, \mathbf{6 e}$, $\mathbf{6 h}$, and $\mathbf{6 i}$ gave rise to induction of HO-1 expression. With the HO-1 promoter-based analysis, we found compounds $\mathbf{6 b}, \mathbf{6 e}, \mathbf{6 h}$, and $\mathbf{6 i}$ induced $\mathrm{HO}-1$ expression through increasing Nrf-2 binding activity. Taken together, compound $\mathbf{6 b}$ may serve as a potential lead compound for developing novel anti-HCV agents.
\end{abstract}

Keywords: 3-amino-2-hydroxypropoxyisoflavones; ribavirin; hepatitis C virus; cytotoxicity

\section{Introduction}

Hepatitis $\mathrm{C}$ virus (HCV) infection has significantly increased in the past decades and becomes a severe problem in liver diseases, including chronic hepatitis, cirrhosis, and hepatocellular carcinoma (HCC). Globally, an estimated 200 million people are infected with hepatitis C virus and more than 350,000 people die every year from HCV-related liver diseases [1-3]. In clinical therapies, there are still no approved vaccines for the treatment of HCV infection [4]. The therapeutic agents for $\mathrm{HCV}$ patients still present a drug-resistant problem, so the development of supplemental agents or more effective and safer agents is required for such therapy [5-10]. Recently, Andreev et al. [11] identified 1-benzyl-2-phenyl-4,5,6,7-tetrahydro- $1 H$-indole 
(Compound 1) as a potent anti-HCV agent which displayed $\mathrm{EC}_{50}$ values of 7.9 and $2.6 \mu \mathrm{M}$ in genotype $1 \mathrm{~b}$ and $2 \mathrm{a}$, respectively. Kaushik-Basu et al. [12] reported that (3aS,8aS,E)-ethyl-4-(2-phenylhydrazono)-1-tosyldecahydro-cyclohepta[b]pyrrole-2-carboxylate (Compound 2) exhibited $\mathrm{EC}_{50}$ values of 1.8 and $4.5 \mu \mathrm{M}$ in genotype $1 \mathrm{~b}$ and $2 \mathrm{a}$, respectively. Zhong et al. [13] prepared certain quercetin analogues for anti-HCV evaluations and found 7-[(3-chlorobenzyl)oxy]-2-(3,4-dihydroxyphenyl)-3,5-dihydroxy-4H-chromen-4-one (Compound 3) was the most potent, exhibiting an $\mathrm{EC}_{50}$ value of $3.8 \mu \mathrm{M}$. We have also synthesized certain naphtho $[1,2-d]$ oxazole derivatives for anti-HCV evaluations and discovered 2-(furan-2-yl)-N-(4-methoxyphenyl)naphtho[1,2-d]oxazol-5-amine (Compound 4) [14] to be the most active, exhibiting an $\mathrm{EC}_{50}$ value of $0.63 \mu \mathrm{M}$.

A number of natural isoflavonoids along with their synthetic analogues have been found to possess extensive biological activities including antiparasitic, anti-cancer, antiviral, anti-inflammatory, antioxidant, and anti-osteoporosis effects [15-19]. In order to further explore antiviral effects of isoflavonoids, we describe herein the synthesis of 3-amino-2-hydroxy-propoxyisoflavone derivatives (target compounds, Figure 1) and their evaluations related to the inhibition of HCV replication by inducing HO-1 expression.

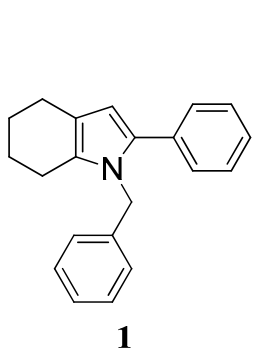<smiles>CCOC(=O)C1CC2/C(=N/Nc3ccccc3)CCCC[C@H]2N1S(=O)(=O)c1ccc(C)cc1</smiles>

2<smiles>O=c1c(O)c(-c2ccc(O)c(O)c2)oc2cc(OCc3cccc(Cl)c3)cc(O)c12</smiles>

3<smiles>COc1ccc(Nc2cc3oc(-c4ccco4)nc3c3ccccc23)cc1</smiles>

4<smiles>[R10]CC(O)COc1ccc2c(=O)c(-c3ccc(OC)c(OC)c3)coc2c1</smiles>

Target compounds

Figure 1. Structures of compounds 1-4, and target compounds.

\section{Results and Discussion}

\subsection{Chemistry}

Preparation of 3-Amino-2-Hydroxypropoxyisoflavone Derivatives

The desired 3-amino-2-hydroxypropoxyisoflavone derivatives, $\mathbf{6 a}-\mathbf{i}$, have been prepared as described in Scheme 1. Reaction of 3-(3,4-dimethoxyphenyl)-7(oxiran-2-ylmethoxy)-4H-chromen-4-one (5) [19] with 4-hydroxyphenylethylamine in ethanol gave 3-(3,4-dimethoxyphenyl)-7-\{2-hydroxy-3- [(4-hydroxyphenethyl) amino]propoxy $\}-4 H$-chromen-4-one $(6 \mathbf{a})$ in 76\% yield. 7-\{3-[(3,4-Dimethoxyphenethyl)amino]2-hydroxypropoxy\}-3-(3,4-dimethoxyphenyl)-4H-chromen- 4-one (6b) was obtained by the treatment of $\mathbf{5}$ with 3,4-dimethoxyphenylethylamine. The structure of $\mathbf{6} \mathbf{b}$ was determined by ${ }^{13} \mathrm{C}(100 \mathrm{MHz})$, ${ }^{1} \mathrm{H}(400 \mathrm{MHz})$, heteronuclear multiple quantum coherence (HMQC), heteronuclear multiple bond correlation (HMBC), and nuclear Overhauser enhancement spectroscopy (NOESY) nuclear magnetic resonance (NMR) (Table 1). The spectra of $\mathbf{6 b}$ (Table 1) revealed the presence of two sets of 
3,4-dimethoxyphenyl-aromatic rings $\left[\delta_{\mathrm{C}} 124.52\left(\mathrm{C}-1^{\prime}\right)\right.$ and $132.05\left(\mathrm{C}-3^{\prime \prime \prime}\right) ; \delta_{\mathrm{C}} 112.42\left(\mathrm{C}-2^{\prime}\right) / \delta_{\mathrm{H}} 7.20$ $\left(2^{\prime}-\mathrm{CH}, \mathrm{d}, J=2.0 \mathrm{~Hz}\right)$ and $\delta_{\mathrm{C}} 111.89\left(\mathrm{C}-4^{\prime \prime \prime}\right) / \delta_{\mathrm{H}} 6.74\left(4^{\prime \prime \prime}-\mathrm{CH}, \mathrm{m}\right) ; \delta_{\mathrm{C}} 148.71\left(\mathrm{C}-3^{\prime}\right)$ and $147.52\left(\mathrm{C}-5^{\prime \prime \prime}\right) ; \delta_{\mathrm{C}}$ $148.94\left(\mathrm{C}-4^{\prime}\right)$ and $149.05\left(\mathrm{C}-6^{\prime \prime \prime}\right) ; \delta_{\mathrm{C}} 111.10\left(\mathrm{C}-5^{\prime}\right) / \delta_{\mathrm{H}} 6.92\left(5^{\prime}-\mathrm{CH}, \mathrm{d}, J=8.4 \mathrm{~Hz}\right)$ and $\delta_{\mathrm{C}} 111.27\left(\mathrm{C}-7^{\prime \prime \prime}\right) / \delta_{\mathrm{H}}$ $6.80\left(7^{\prime \prime \prime}-\mathrm{CH}, \mathrm{d}, J=8.0 \mathrm{~Hz}\right) ; \delta_{\mathrm{C}} 120.98\left(\mathrm{C}-6^{\prime}\right) / \delta_{\mathrm{H}} 7.04\left(6^{\prime}-\mathrm{CH}, \mathrm{dd}, J=8.4,2.0 \mathrm{~Hz}\right)$ and $\delta_{\mathrm{C}} 20.55\left(\mathrm{C}-8^{\prime \prime \prime}\right) / \delta_{\mathrm{H}}$ $6.75(\mathrm{~m})]$, four methoxy groups $\left[\delta_{\mathrm{C}} 55.89 / \delta_{\mathrm{H}} 3.84(\mathrm{~s})\right.$ for $3^{\prime}-\mathrm{OMe}, \delta_{\mathrm{C}} 55.91 / \delta_{\mathrm{H}} 3.88(\mathrm{~s})$ for $4^{\prime}-\mathrm{OMe}, \delta_{\mathrm{C}}$ $55.82 / \delta_{\mathrm{H}} 3.91(\mathrm{~s})$ for $5^{\prime \prime \prime}$-OMe, and $\delta_{\mathrm{C}} 55.87 / \delta_{\mathrm{H}} 3.93(\mathrm{~s})$ for $6^{\prime \prime \prime}$-OMe], $4 H$-chromen-4-one moiety $\left[\delta_{\mathrm{C}}\right.$ $152.26(\mathrm{C}-2) / \delta_{\mathrm{H}} 7.94(2-\mathrm{CH}, \mathrm{s}), \delta_{\mathrm{C}} 124.89(\mathrm{C}-3), \delta_{\mathrm{C}} 75.81(\mathrm{C}-4), \delta_{\mathrm{C}} 118.55(\mathrm{C}-4 \mathrm{a}), \delta_{\mathrm{C}} 127.75(\mathrm{C}-5) / \delta_{\mathrm{H}}$ $8.20(5-\mathrm{CH}, \mathrm{d}, J=8.8 \mathrm{~Hz}), \delta_{\mathrm{C}} 114.74(\mathrm{C}-6) / \delta_{\mathrm{H}} 6.99(6-\mathrm{CH}, \mathrm{d}, J=8.8,2.4 \mathrm{~Hz}), \delta_{\mathrm{C}} 162.95(\mathrm{C}-7), \delta_{\mathrm{C}} 157.73$ $(\mathrm{C}-8) / \delta_{\mathrm{H}} 6.86(8-\mathrm{CH}, \mathrm{d}, J=2.4 \mathrm{~Hz})$, and $\left.\delta_{\mathrm{C}} 157.73(\mathrm{C}-8 \mathrm{a})\right]$, and the 3-amino-2-hydroxypropoxy-spacer $\left[\delta_{\mathrm{C}} 67.72\left(\mathrm{C}-1^{\prime \prime}\right) / \delta_{\mathrm{H}} 4.07\left(1^{\prime \prime}-\mathrm{CH}_{2}, \mathrm{~m}\right), \delta_{\mathrm{C}} 70.95\left(\mathrm{C}-2^{\prime \prime}\right) / \delta_{\mathrm{H}} 4.07\left(2^{\prime \prime}-\mathrm{CH}, \mathrm{m}\right), \delta_{\mathrm{C}} 51.32\left(\mathrm{C}-3^{\prime \prime}\right) / \delta_{\mathrm{H}} 2.91\right.$ $\left(3^{\prime \prime}-\mathrm{CH}_{2}, \mathrm{~m}\right), \delta_{\mathrm{C}} 50.98\left(\mathrm{C}-1^{\prime \prime \prime}\right) / \delta_{\mathrm{H}} 2.91$ and $2.78\left(1^{\prime \prime \prime}-\mathrm{CH}_{2}, \mathrm{~m}\right), \delta_{\mathrm{C}} 35.85\left(\mathrm{C}-2^{\prime \prime \prime}\right) / \delta_{\mathrm{H}} 2.78\left(2^{\prime \prime \prime}-\mathrm{CH}_{2}, \mathrm{~m}\right)$, and $\delta_{\mathrm{H}} 2.23$ (2"-OH and $3^{\prime \prime}-\mathrm{NH}, \mathrm{br}$ ) ]. Its HMBC spectrum provided key correlations: (1) from H-2' to $\mathrm{C}-3,4^{\prime}, 6^{\prime}$, and $\mathrm{H}-6^{\prime}$ to $\mathrm{C}-3,2^{\prime}, 4^{\prime}$ suggested the 3,4-dimethoxyphenyl group was attached to $\mathrm{C}-3$ of the $4 \mathrm{H}$-chromen-4-one moiety; (2) from $\mathrm{H}-1^{\prime \prime}$ to $\mathrm{C}-7,3^{\prime \prime}, \mathrm{H}-1^{\prime \prime \prime}$ to $\mathrm{C}-3^{\prime \prime}, 3^{\prime \prime \prime}$ indicated the other 3,4-dimethoxyphenyl group was attached to C-2'" of the 3-amino-2-hydroxypropoxy-spacer and the spacer was attached to $\mathrm{C}-7$ of the $4 \mathrm{H}$-chromen-4-one moiety (Figure $2 \mathrm{~A}$ ). The relative connection was established according to nuclear Overhauser effect (NOE) correlations between $\mathrm{H}-2 / \mathrm{H}-2^{\prime}, 6^{\prime}$; $\mathrm{H}-1^{\prime \prime} / \mathrm{H}-6,8 ; \mathrm{H}-1^{\prime \prime \prime} / \mathrm{H}-2^{\prime \prime}, 8^{\prime \prime \prime}$; and H-2'" /H-8'" in the NOESY experiment (Figure 2B). Accordingly, compounds $6 \mathbf{c}-6 \mathbf{i}$ have been prepared by amination of 5 in a yield of $65-83 \%$. The structure of $6 \mathbf{a}-\mathbf{i}$ was determined by NMR $\left({ }^{1} \mathrm{H}\right.$ and ${ }^{13} \mathrm{C}$ ) (spectra data can be found in Supplementary Materials) and further confirmed by elemental analysis.

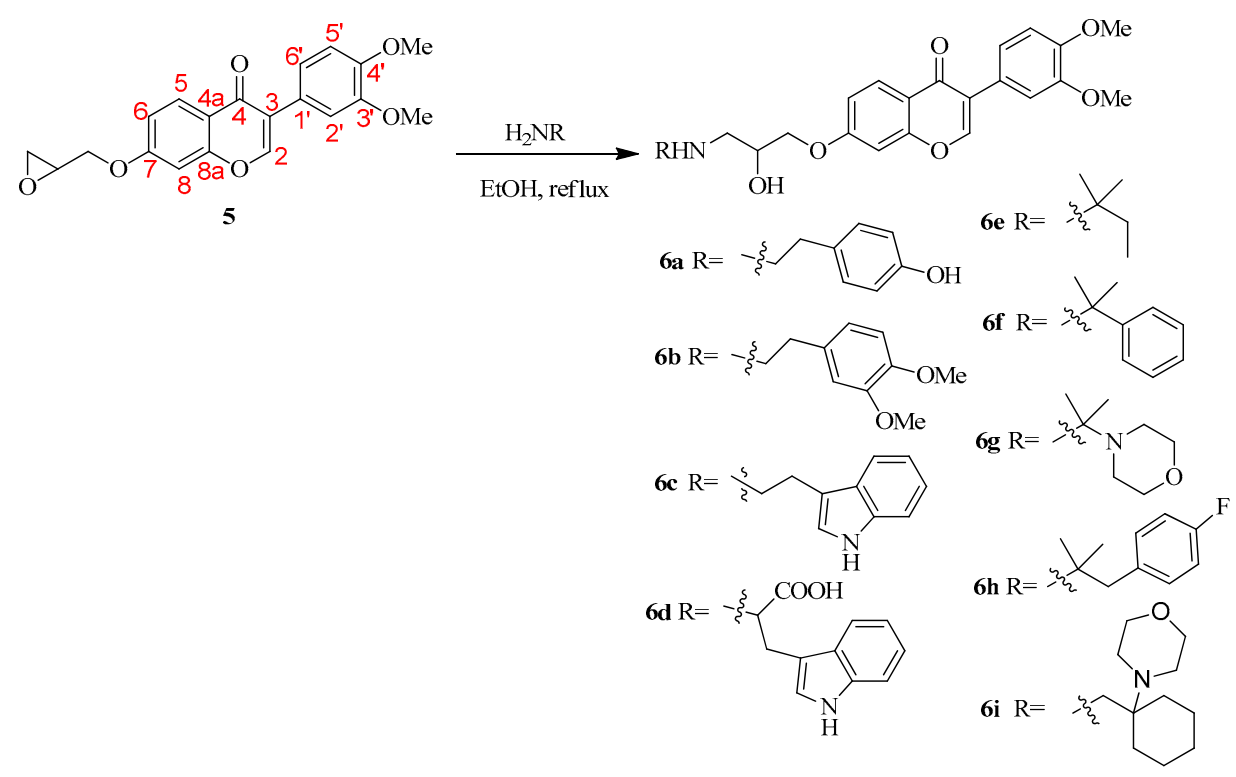

Scheme 1. Synthesis of 3-amino-2-hydroxypropoxyisoflavone derivatives 6a-i. 
Table 1. ${ }^{13} \mathrm{C}(100 \mathrm{MHz}),{ }^{1} \mathrm{H}(400 \mathrm{MHz}), \quad \mathrm{HC}$ HMBC and NOESY nuclear magnetic resonance (NMR) Data for 7-\{3-[(3,4-dimethoxy phenethyl)amino]-2-hydroxypropoxy\}-3(3,4-dimethoxyphenyl)-4H-chromen-4-one (6b) in $\mathrm{CDCl}_{3}$. ${ }^{\mathrm{a}}$

\begin{tabular}{|c|c|c|c|c|}
\hline \multicolumn{2}{|c|}{${ }^{13} \mathrm{C}$} & \multicolumn{2}{|l|}{${ }^{1} \mathbf{H}^{b}$} & \multirow[b]{2}{*}{ NOESY } \\
\hline Position & $\delta_{C}$ (mult.) & $\delta_{\mathrm{H}}$ (mult., $\left.J, \mathrm{~Hz}\right)$ & НС НМВС & \\
\hline 2 & $152.26(\mathrm{CH})$ & $7.94(\mathrm{~s})$ & $4,8 \mathrm{a}, 1^{\prime}$ & $2^{\prime}, 6^{\prime}$ \\
\hline 3 & $124.89(\mathrm{C})$ & & & \\
\hline 4 & $175.81(\mathrm{C})$ & & & \\
\hline $4 a$ & $118.55(\mathrm{C})$ & & & \\
\hline 5 & $127.75(\mathrm{CH})$ & $8.20(\mathrm{~d}, 8.8)$ & $4,7,8 \mathrm{a}$ & 6 \\
\hline 6 & $114.74(\mathrm{CH})$ & $6.99(\mathrm{dd}, 8.8,2.4)$ & $4 a, 8$ & $5,1^{\prime \prime}$ \\
\hline 7 & $162.95(\mathrm{C})$ & & & \\
\hline 8 & $100.84(\mathrm{CH})$ & $6.86(\mathrm{~d}, 2.4)$ & $4 a, 6,7,8 a$ & $1^{\prime \prime}$ \\
\hline $8 a$ & $157.73(\mathrm{C})$ & & & \\
\hline $1^{\prime}$ & $124.52(\mathrm{C})$ & & & \\
\hline $2^{\prime}$ & $112.42(\mathrm{CH})$ & $7.20(\mathrm{~d}, 2.0)$ & $3,4^{\prime}, 6^{\prime}$ & $2,3^{\prime}-\mathrm{OMe}$ \\
\hline $3^{\prime}$ & $148.71(\mathrm{C})$ & & & \\
\hline $3^{\prime}-\mathrm{OMe}$ & $55.89\left(\mathrm{CH}_{3}\right)$ & $3.84(\mathrm{~s})$ & & $2^{\prime}$ \\
\hline $4^{\prime}$ & $148.94(\mathrm{C})$ & & & \\
\hline $4^{\prime}-\mathrm{OMe}$ & $55.91\left(\mathrm{CH}_{3}\right)$ & $3.88(\mathrm{~s})$ & & $5^{\prime}$ \\
\hline $5^{\prime}$ & $111.10(\mathrm{CH})$ & $6.92(\mathrm{~d}, 8.4)$ & $1^{\prime}, 3^{\prime}$ & $6^{\prime}, 4^{\prime}-\mathrm{OMe}$ \\
\hline $6^{\prime}$ & $120.98(\mathrm{CH})$ & $7.04(\mathrm{dd}, 8.4,2.0)$ & $3,2^{\prime}, 4^{\prime}$ & $2,5^{\prime}$ \\
\hline $1^{\prime \prime}$ & $67.72\left(\mathrm{CH}_{2}\right)$ & $4.07(\mathrm{~m})$, overlapped & $7,3^{\prime \prime}$ & 6,8 \\
\hline $2^{\prime \prime}$ & $70.95(\mathrm{CH})$ & $4.07(\mathrm{~m})$, overlapped & & $3^{\prime \prime}, 1^{\prime \prime \prime}$ \\
\hline $2 "-\mathrm{OH}$ & & 2.23 (br s), overlapped & & \\
\hline $3^{\prime \prime}$ & $51.32\left(\mathrm{CH}_{2}\right)$ & $2.91(\mathrm{~m})$, overlapped & & $2 "$ \\
\hline 3"-NH & & 2.23 (br s), overlapped & & \\
\hline $1^{\prime \prime \prime}$ & $50.98\left(\mathrm{CH}_{2}\right)$ & 2.91 and $2.78(\mathrm{~m})$, overlapped & $3^{\prime \prime}, 3^{\prime \prime \prime}$ & $2^{\prime \prime}, 8^{\prime \prime \prime}$ \\
\hline $2^{\prime \prime \prime}$ & $35.85\left(\mathrm{CH}_{2}\right)$ & $2.78(\mathrm{~m})$, overlapped & $4^{\prime \prime \prime}, 8^{\prime \prime \prime}$ & $8^{\prime \prime \prime}$ \\
\hline $3^{\prime \prime \prime}$ & $132.05(\mathrm{C})$ & & & \\
\hline $4^{\prime \prime \prime}$ & $111.89(\mathrm{CH})$ & $6.74(\mathrm{~m})$, overlapped & $2^{\prime \prime \prime}, 6^{\prime \prime \prime}, 8^{\prime \prime \prime}$ & $5^{\prime \prime \prime}-\mathrm{OMe}$ \\
\hline $5^{\prime \prime \prime}$ & $147.52(\mathrm{C})$ & & & \\
\hline $5^{\prime \prime \prime}-\mathrm{OMe}$ & $55.82\left(\mathrm{CH}_{3}\right)$ & $3.91(\mathrm{~s})$ & & $4^{\prime \prime \prime}$ \\
\hline $6^{\prime \prime \prime}$ & $149.05(\mathrm{C})$ & & & \\
\hline $6^{\prime \prime \prime}-\mathrm{OMe}$ & $55.87\left(\mathrm{CH}_{3}\right)$ & $3.93(\mathrm{~s})$ & & $7^{\prime \prime \prime}$ \\
\hline $7^{\prime \prime \prime}$ & $111.27(\mathrm{CH})$ & $6.80(\mathrm{~d}, 8.0)$ & $3^{\prime \prime \prime}$ & $6^{\prime \prime \prime}-\mathrm{OMe}$ \\
\hline $8^{\prime \prime \prime}$ & $120.55(\mathrm{CH})$ & $6.75(\mathrm{~m})$, overlapped & $2^{\prime \prime \prime}, 4^{\prime \prime \prime}, 6^{\prime \prime \prime}$ & $1^{\prime \prime \prime}, 2^{\prime \prime \prime}$ \\
\hline
\end{tabular}

${ }^{a}$ s: Singlet, d: Doublet, dd: Doublet of doublets, br s: Broad singlet, m: Multiple, ov: Overlapped; ${ }^{b}$ The $^{13} \mathrm{C}$ and ${ }^{1} \mathrm{H}$ correlations were confirmed by the heteronuclear multiple quantum coherence (HMQC) experiment.

(A)

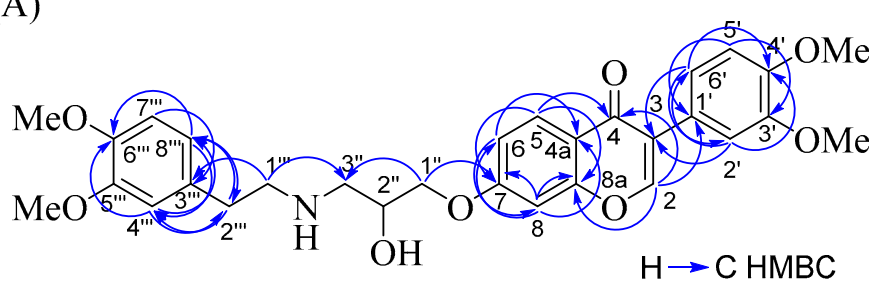

(B)

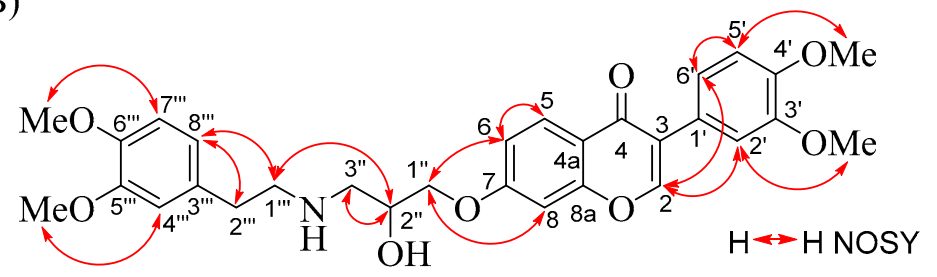

Figure 2. HMBC (A) and NOESY (B) correlations for 7-\{3-[(3,4-dimethoxyphenethyl)amino]2-hydroxypropoxy\}-3-(3,4-dimethoxyphenyl)-4H-chromen-4-one (6b). 


\subsection{Biological Activities}

\subsubsection{Anti-HCV Activities and Cytotoxicities}

The anti-HCV and cytotoxicities of 3-amino-2-hydroxypropoxyisoflavone derivatives are summarized in Table 2. Ava-5 cells were treated with compounds $6 \mathbf{a}-\mathbf{i}$ or the positive ribavirin for three days, and then analyzed through firefly luciferase assay. The concentration that inhibited $50 \%$ $\mathrm{HCV}$ replication $\left(\mathrm{EC}_{50}\right)$, the concentration that inhibited $50 \%$ cell growth $\left(\mathrm{CC}_{50}\right)$, and the selectivity index (SI: $\mathrm{CC}_{50} / \mathrm{EC}_{50}$ ) of compounds were determined with ribavirin as a positive control. Results indicated that compounds $\mathbf{6 b}, \mathbf{6 e}, \mathbf{6 h}$ and $\mathbf{6 i}$ were more active than ribavirin. Among them, compound $\mathbf{6 b}$ was the most active, exhibiting approximately 2-fold more anti-HCV activity $\left(\mathrm{EC}_{50}\right.$ of $\left.6.53 \mu \mathrm{M}\right)$ than that of ribavirin $\left(\mathrm{EC}_{50}=13.16 \mu \mathrm{M}\right)$. In addition, compound $\mathbf{6} \mathbf{b}$ was less cytotoxic than ribavirin. The selectivity index (SI) of $\mathbf{6} \mathbf{b}$ is approximately 2.6 -fold higher than that of ribavirin (21.08 vs. 8.08).

Table 2. Antiviral activities and cytotoxicities of isoflavone derivatives.

\begin{tabular}{cccc}
\hline Compound & $\mathbf{E C}_{\mathbf{5 0}}(\boldsymbol{\mu M})^{\mathbf{a}}$ & $\mathbf{C C}_{\mathbf{5 0}}(\boldsymbol{\mu M})^{\mathbf{b}}$ & SI $^{\mathbf{c}}$ \\
\hline $\mathbf{6 a}$ & $>20$ & $71.65 \pm 4.44$ & $<3.58$ \\
$\mathbf{6 b}$ & $6.53 \pm 0.57$ & $137.68 \pm 6.91$ & 21.08 \\
$\mathbf{6} \mathbf{c}$ & $16.32 \pm 0.95$ & $36.93 \pm 0.46$ & 2.26 \\
$\mathbf{6 d}$ & $>20$ & $98.84 \pm 3.67$ & $<4.94$ \\
$\mathbf{6 e}$ & $8.14 \pm 1.74$ & $87.91 \pm 2.13$ & 10.80 \\
$\mathbf{6 f}$ & $14.31 \pm 0.84$ & $47.19 \pm 2.74$ & 3.30 \\
$\mathbf{6 g}$ & $>20$ & $143.57 \pm 3.82$ & $<7.17$ \\
$\mathbf{6} \mathbf{h}$ & $9.35 \pm 0.97$ & $110.98 \pm 4.39$ & 11.87 \\
$\mathbf{6 i}$ & $10.71 \pm 0.87$ & $155.87 \pm 1.58$ & 14.55 \\
ribavirin & $13.16 \pm 1.63$ & $106.27 \pm 3.69$ & 8.08 \\
\hline
\end{tabular}

a The $\mathrm{EC}_{50}$ is the concentration of the compound resulting in a $50 \%$ inhibition in virus production; ${ }^{\mathrm{b}} \mathrm{The}_{\mathrm{CC}}$ is the concentration of the compound causing a $50 \%$ growth inhibition of uninfected ava- 5 cells; ${ }^{\mathrm{c}}$ SI: Selectivity index. $\mathrm{SI}=\mathrm{CC}_{50} / \mathrm{IC}_{50}$.

\subsubsection{Compound $\mathbf{6 b}$ Reduced HCV Replication in HCV-Infected Ava-5 Cells}

To further confirm the anti-HCV effect of compound $\mathbf{6 b}$, we treated compound $\mathbf{6 b}$ at indicated concentrations in Ava-5 cells for 3 days. Both western blotting and RT-qPCR were performed to determine the resultant activity of compound $\mathbf{6 b}$ against $\mathrm{HCV}$ replication showing that compound $\mathbf{6 b}$ dose-dependently reduced HCV protein synthesis and RNA replication without cell cytotoxicity in Ava 5 cells. Treatment of $0.1 \%$ dimethyl sulfoxide (DMSO) served as a mock control on inhibition of HCV replication (Figures 3 and 4). 


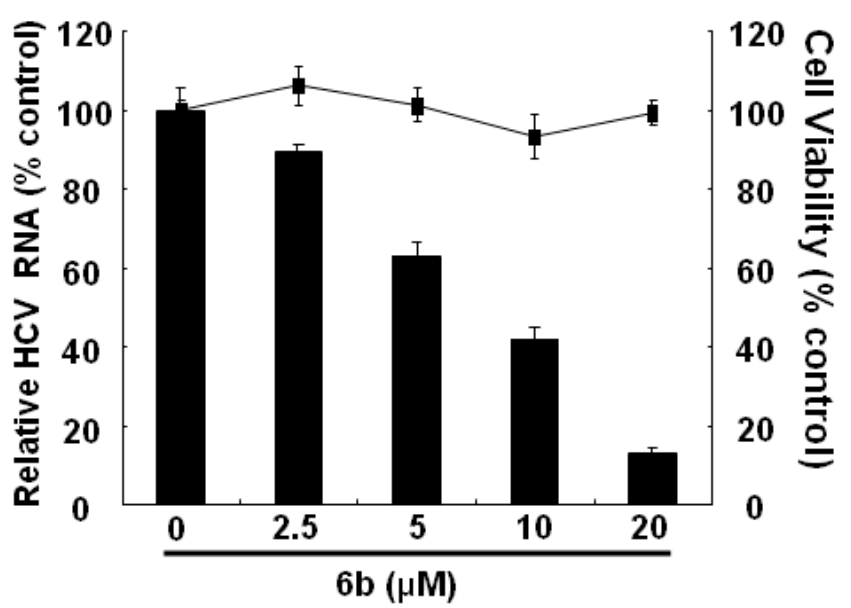

Figure 3. Inhibition of HCV RNA expression in HCV-infected Ava-5 cells by 6 b. Ava-5 cells were treated with $2.5,5,10$ and $20 \mu \mathrm{M}$ of $\mathbf{6 b}$ for 3 days. Total RNA was extracted and quantified HCV RNA levels by RT-qPCR. HCV RNA expression was normalized by cellular GAPDH mRNA. Treatment with $0.1 \%$ DMSO served as a mock control. The results are expressed as the means \pm standard deviations (SD) of triplicate experiments.

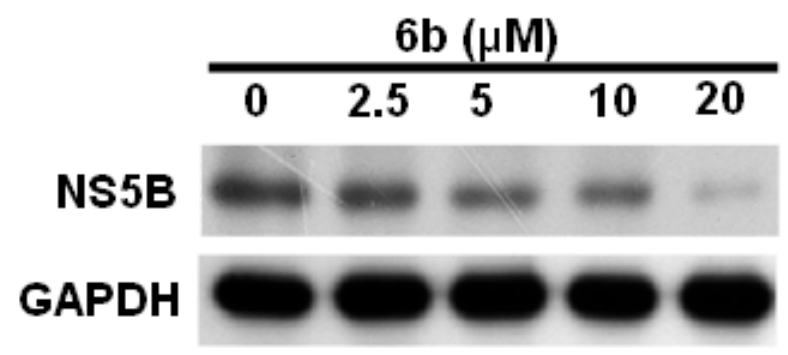

Figure 4. Inhibition of HCV protein synthesis in Ava- 5 cells by 6b. Ava-5 cells were treated with 2.5, 5,10 and $20 \mu \mathrm{M}$ of $\mathbf{6 b}$ for 3 days. Total cell lysate was collected for performing western blotting to analyze HCV protein synthesis. Levels of GAPDH were used as equal loading control.

\subsubsection{Isoflavones Reduced HCV Replication through Inducing HO-1 Protein Expression}

In our previous studies, we found that induction of HO-1 protein level could suppress $\mathrm{HCV}$ replication $[14,20]$. To determine whether compounds $\mathbf{6} \mathbf{b}, \mathbf{6 e}, \mathbf{6} \mathbf{h}$ and $\mathbf{6} \mathbf{i}$ have impact on HO-1 protein expression in Ava-5 cells, we treated these compounds at $10 \mu \mathrm{M}$ in Ava5 cells. Results indicated that compounds $\mathbf{6 b}, \mathbf{6 e}, \mathbf{6} \mathbf{h}$ and $\mathbf{6 i}$ could induce HO-1 protein level in Ava-5 cells, compared with the DMSO-treated Ava5 cells (Figure 5).

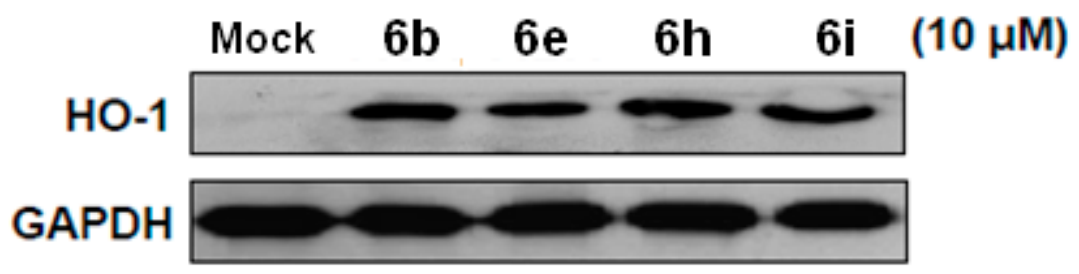

Figure 5. Compounds induced HO-1 protein expression in Ava-5 cells. Compound $\mathbf{6 b}, \mathbf{6 e}, \mathbf{6 h}$ and $\mathbf{6 i}$ induced HO-1 protein expression. Ava- 5 cells were treated with compounds at $10 \mu \mathrm{M}$ for 3 days. The cell lysate was subjected to western blotting with anti-HO-1 and anti-GAPDH antibodies.

\subsubsection{Isoflavones Up-Regulates Nrf2 Transactivating HO-1 Expression to Inhibit HCV Replication}

Heme oxygenase 1 expression is regulated by the transcription factors Nrf2, Keap1, and Bach1 through the binding of ARE in its promoter region [21-23]; therefore, we determined whether isoflavones-mediated HO-1 induction was dependent on ARE transactivation by treating 
p3xARE-Luc-transfected ava-5 cells with increasing concentrations of sulforaphane (SFN) for 3 days. As shown in Figure 6, compounds 6b, 6e, 6h and $\mathbf{6 i}$ increased ARE-mediated luciferase activity. Taken together, these results suggest that the anti-HCV activity of isoflavones were dependent on Nrf2-mediated HO-1 induction.

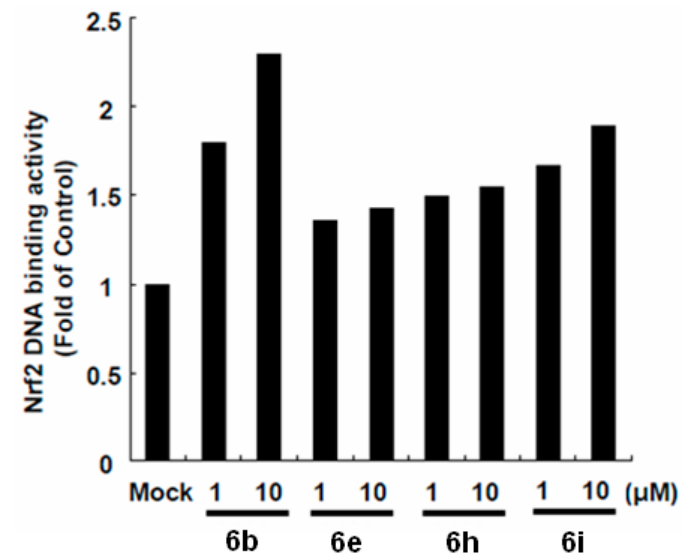

Figure 6. Isoflavones inhibited HCV replication by upregulating Nrf2 expression. Compound $\mathbf{6 b}, \mathbf{6 e}$, 6h and $6 \mathbf{i}$ stimulated ARE transactivation in Ava-5 cells. The antioxidant response reporter plasmid, p3xARE-Luc, was transfected into Ava- 5 cells and then treated with isoflavones ( 1 and $10 \mu \mathrm{M})$ for 3 days. The relative induction of antioxidant activity was determined by luciferase assay. The activity of untreated Ava- 5 cells was considered to be 1 .

\section{Experimental}

\subsection{Materials and Methods}

\subsubsection{Chemical Reactions}

\section{General}

Melting points were determined on an Electrothermal IA9100 melting point apparatus and are uncorrected. Nuclear magnetic resonance $\left({ }^{1} \mathrm{H}\right)$ spectra were recorded on a Varian-Unity-400 spectrometer (Varian, Palo Alto, CA, USA). Chemical shifts were expressed in parts per million $(\delta)$ with tetramethylsilane (TMS) as an internal standard. Thin-layer chromatography was performed on silica gel 60 F-254 plates purchased from E. Merck and Co. (Darmstadt, Germany). The elemental analyses were performed in the Instrument Center of Ministry of Science and Technology at National Cheng-Kung University and National Taiwan University using Heraeus CHN-O Rapid EA (Heraeus, Waltham, MA, USA), and all values are within $\pm 0.4 \%$ of the theoretical compositions.

General Procedure for the Preparation of 3-Amino-2-Hydroxypropoxyisoflavone Compounds 6a-i

To a suspension of $5(1.0 \mathrm{mmol})$ in ethanol $(15 \mathrm{~mL})$ was added substituted amines $(3.0 \mathrm{mmol})$. The reaction mixture was refluxed for $3 \mathrm{~h}$ (TLC monitoring). The solvent was removed in vacuo and the residue suspended in $\mathrm{H}_{2} \mathrm{O}(20 \mathrm{~mL})$. The crude product was purified by flash chromatography on silica gel and recrystallized from $\mathrm{MeOH}$ to afford the 3-amino-2-hydroxypropoxyisoflavone products.

3-(3,4-Dimethoxyphenyl)-7-\{2-hydroxy-3-[(4-hydroxyphenethyl)amino]propoxy\}-4H-chromen-4-one (6a): Yield 76\%. Mp: $117-118{ }^{\circ} \mathrm{C} .{ }^{1} \mathrm{H}$ NMR (400 MHz, DMSO-d 6 ): $\delta 9.18$ (br s, $\left.1 \mathrm{H}\right), 8.46$ (s, 1H, H-2), 8.04 (d, $J=8.8 \mathrm{~Hz}, 1 \mathrm{H}, \mathrm{H}-5), 7.21\left(\mathrm{~d}, J=2.0 \mathrm{~Hz}, 1 \mathrm{H}, \mathrm{H}-2^{\prime}\right), 7.17-7.14\left(\mathrm{~m}, 2 \mathrm{H}, \mathrm{H}-8, \mathrm{H}-6^{\prime}\right), 7.08(\mathrm{dd}, 1 \mathrm{H}, J=8.8,2.4$ Hz, H-6), 7.02 (d, J = 8.4 Hz, 1H, H-5'), 7.01-6.98 (m, 2H), 6.68-6.65 (m, 2H), 5.17 (br s, 1H), 4.15-4.11 $(\mathrm{m}, 1 \mathrm{H}), 4.05-4.01(\mathrm{~m}, 1 \mathrm{H}), 3.96-3.92(\mathrm{~m}, 1 \mathrm{H}), 3.79(\mathrm{~s}, 6 \mathrm{H}), 2.75-2.59(\mathrm{~m}, 6 \mathrm{H}) .{ }^{13} \mathrm{C} \mathrm{NMR}(100 \mathrm{MHz}$, DMSO-d $\left.)_{6}\right): \delta 174.66(\mathrm{C}-4), 163.16(\mathrm{C}-7), 157.38(\mathrm{C}-8 \mathrm{a}), 155.48,153.71(\mathrm{C}-2), 148.66\left(\mathrm{C}-4^{\prime}\right), 148.30\left(\mathrm{C}-3^{\prime}\right)$, 130.24, 129.46 (2C), 126.98 (C-5), 124.39 (C-1'), 123.48 (C-3), 121.27 (C-6'), 117.58 (C-4a), 115.17 (C-6), 
115.06 (2C), $112.74\left(\mathrm{C}-2^{\prime}\right), 111.54\left(\mathrm{C}-5^{\prime}\right), 101.09$ (C-8), 71.60, 67.84, 55.54 (3'-OMe-3', 4'-OMe), 51.99, 51.44, 34.91. Anal. calcd. for $\mathrm{C}_{28} \mathrm{H}_{29} \mathrm{NO}_{7} \cdot 1.2 \mathrm{H}_{2} \mathrm{O}$ : C 65.54, $\mathrm{H}$ 6.17, N 2.73; found: C 65.50, H 6.06, N 2.59.

7-\{3-[(3,4-Dimethoxyphenethyl)amino]-2-hydroxypropoxy\}-3-(3,4-dimethoxyphenyl)-4H-chromen-4-one (6b): Yield 69\%. Mp: $134-135{ }^{\circ} \mathrm{C} .{ }^{1} \mathrm{H}$ NMR $\left(400 \mathrm{MHz}, \mathrm{CDCl}_{3}\right): \delta 8.20(\mathrm{~d}, 1 \mathrm{H}, J=8.8 \mathrm{~Hz}, \mathrm{H}-5), 7.94(\mathrm{~s}, 1 \mathrm{H}$, $\mathrm{H}-2), 7.20\left(\mathrm{~d}, 1 \mathrm{H}, J=2.0 \mathrm{~Hz}, \mathrm{H}-2^{\prime}\right), 7.04\left(\mathrm{dd}, 1 \mathrm{H}, J=8.4,2.0 \mathrm{~Hz}, \mathrm{H}-6^{\prime}\right), 6.99(\mathrm{dd}, 1 \mathrm{H}, J=8.8,2.4 \mathrm{~Hz}$, H-6), $6.92\left(\mathrm{~d}, 1 \mathrm{H}, J=8.4 \mathrm{~Hz}, \mathrm{H}-5^{\prime}\right), 6.86(\mathrm{~d}, 1 \mathrm{H}, J=2.4 \mathrm{~Hz}, \mathrm{H}-8), 6.80(\mathrm{~d}, 1 \mathrm{H}, J=8.0 \mathrm{~Hz}), 6.77-6.74(\mathrm{~m}$, $2 \mathrm{H}), 4.10-4.04(\mathrm{~m}, 3 \mathrm{H}), 3.93(\mathrm{~s}, 3 \mathrm{H}), 3.91(\mathrm{~s}, 3 \mathrm{H}), 3.88(\mathrm{~s}, 3 \mathrm{H}), 3.86(\mathrm{~s}, 3 \mathrm{H}), 2.99-2.74(\mathrm{~m}, 6 \mathrm{H}), 2.23(\mathrm{br} \mathrm{s}$, 2H, OH and NH). ${ }^{13} \mathrm{C}$ NMR (100 MHz, CDCl $) \delta 175.81$ (C-4), 162.95 (C-7), 157.73 (C-8a), 152.26 (C-2), 149.10, $148.99\left(\mathrm{C}-4^{\prime}\right), 148.77\left(\mathrm{C}-3^{\prime}\right), 147.57,132.14,127.81$ (C-5), $124.94\left(\mathrm{C}-1^{\prime}\right), 124.57(\mathrm{C}-3), 121.02\left(\mathrm{C}-6^{\prime}\right)$, 120.59, 118.62 (C-4a), 114.77 (C-6), 112.48 (C-2') , 111.95, 111.34 (C-5'), 111.16, 100.89 (C-8), 70.98, 67.78, $55.95,55.93,55.91$ (4'-OMe), 55.86 (3'-OMe), 51.31, 51.02, 35.95. Anal. calcd. for $\mathrm{C}_{30} \mathrm{H}_{33} \mathrm{NO}_{8}$ : C 67.28, $\mathrm{H}$ 6.21, N 2.62; found: C 66.91, H 6.31, N 2.57.

7-\{3-\{[2-(1H-Indol-3-yl)ethyl]amino\}-2-hydroxypropoxy\}-3-(3,4-dimethoxyphenyl)-4H-chromen-4-one (6c): Yield 65\%. Mp: $178-179{ }^{\circ} \mathrm{C} .{ }^{1} \mathrm{H}$ NMR $\left(400 \mathrm{MHz}, \mathrm{DMSO}-d_{6}\right): \delta 10.80$ (br s, $\left.1 \mathrm{H}\right), 8.45$ (s, $\left.1 \mathrm{H}, \mathrm{H}-2\right)$, $8.04(\mathrm{~d}, 1 \mathrm{H}, J=8.8 \mathrm{~Hz}, \mathrm{H}-5), 7.53-7.51(\mathrm{~m}, 1 \mathrm{H}), 7.34-7.32(\mathrm{~m}, 1 \mathrm{H}), 7.21\left(\mathrm{~d}, 1 \mathrm{H}, J=2.0 \mathrm{~Hz}, \mathrm{H}-2^{\prime}\right), 7.17-7.14$ (m, 3H), 7.09-7.04 (m, 2H), $7.01\left(\mathrm{~d}, 1 \mathrm{H}, J=8.4 \mathrm{~Hz}, \mathrm{H}-5^{\prime}\right), 6.98-6.94(\mathrm{~m}, 1 \mathrm{H}), 5.14(\mathrm{br} \mathrm{s}, 1 \mathrm{H}), 4.17-4.13$ (m, 1H), 4.06-4.02 (m, 1H), 3.98-3.93 (m, 1H), $3.79(\mathrm{~s}, 6 \mathrm{H}), 2.86$ (br s, 4H), 2.77-2.66 (m, 2H). ${ }^{13} \mathrm{C}$ NMR (100 MHz, DMSO-d $\left.d_{6}\right): \delta 174.66$ (C-4), 163.19 (C-7), 157.39 (C-8a), 153.70 (C-2), 148.65 (C-4' ), 148.30 (C-3') 136.26, 127.28, 126.97 (C-5), 124.39 (C-1'), 123.47 (C-3), 122.62, 121.27 (C-6'), 120.87, 118.34, 118.16, 117.57 (C-4a), 115.17 (C-6), 112.72 (C-2'), 112.48, 111.54 (C-5'), 111.37, 101.09 (C-8), 71.66, 67.96, 55.56 (4'-OMe), 55.54 (3'-OMe), 52.11, 50.27, 25.51. Anal. calcd. for $\mathrm{C}_{30} \mathrm{H}_{30} \mathrm{~N}_{2} \mathrm{O}_{6} \cdot 0.2 \mathrm{H}_{2} \mathrm{O}: \mathrm{C} 69.53, \mathrm{H} 5.92, \mathrm{~N}$ 5.41; found: C 69.35, H 5.86, N 5.33 .

3-\{\{3-\{[3-(3,4-Dimethoxyphenyl)-4-oxo-4H-chromen-7-yl]oxy\}-2-hydroxypropyl\}amino\}-2-(1H-indol-3-yl) propanoic acid (6d): Yield 71\%. Mp: $221-222{ }^{\circ} \mathrm{C} .{ }^{1} \mathrm{H}$ NMR $\left(400 \mathrm{MHz}, \mathrm{DMSO}-d_{6}\right): \delta 10.91$ (br s, $\left.1 \mathrm{H}\right), 8.44$ (s, 1H, H-2), $8.02(\mathrm{~d}, 1 \mathrm{H}, J=8.8 \mathrm{~Hz}, \mathrm{H}-5), 7.57\left(\mathrm{~d}, 1 \mathrm{H}, J=7.6 \mathrm{~Hz}, \mathrm{H}-2^{\prime}\right), 7.33(\mathrm{~d}, 1 \mathrm{H}, J=7.6 \mathrm{~Hz}), 7.22-6.94$ $(\mathrm{m}, 8 \mathrm{H}), 4.07-3.96(3 \mathrm{~m}, 3 \mathrm{H}), 3.78(\mathrm{~s}, 6 \mathrm{H}), 3.24-2.74(\mathrm{~m}, 6 \mathrm{H}) .{ }^{13} \mathrm{C}$ NMR $\left(100 \mathrm{MHz}, \mathrm{DMSO}-d_{6}\right): \delta 174.68$ (C-4), 172.50, 162.90 (C-7), 157.34 (C-8a), 153.77 (C-2), 148.66 (C-4'), 148.30 (C-3'), 136.21, 127.35 (C-5), 127.00, 124.37 (C-1'), 123.91, 123.50 (C-3), 121.29 (C-6'), 121.00, 118.55, 118.39, 117.69 (C-4a), 115.13 (C-6), 112.69 (C-2'), $111.52\left({\left.\mathrm{C}-5^{\prime}\right)}^{\prime}\right)$ 111.40, 109.69, 101.14 (C-8), 70.96, 66.42, 62.27, 55.57 (4'-OMe), 55.55 (3'-OMe), 49.66, 27.15. Anal. calcd. for $\mathrm{C}_{31} \mathrm{H}_{30} \mathrm{~N}_{2} \mathrm{O}_{8} \cdot 1.5 \mathrm{H}_{2} \mathrm{O}$ : C 63.57, $\mathrm{H} 5.69, \mathrm{~N}$ 4.78; found: $\mathrm{C} 63.22, \mathrm{H}$ $5.54, \mathrm{~N} 4.81$.

3-(3,4-Dimethoxyphenyl)-7-(2-hydroxy-3-(tert-pentylamino)propoxy)-4H-chromen-4-one (6e): Yield 80\%. Mp: 111-112 ${ }^{\circ} \mathrm{C} .{ }^{1} \mathrm{H}$ NMR $\left(400 \mathrm{MHz}, \mathrm{CDCl}_{3}\right): \delta 8.21(\mathrm{~d}, 1 \mathrm{H}, J=9.2 \mathrm{~Hz}, \mathrm{H}-5), 7.95(\mathrm{~s}, 1 \mathrm{H}, \mathrm{H}-2), 7.21(\mathrm{~d}, 1 \mathrm{H}$, $\left.J=2.0 \mathrm{~Hz}, \mathrm{H}-2^{\prime}\right), 7.06-7.01\left(\mathrm{~m}, 2 \mathrm{H}, \mathrm{H}-6, \mathrm{H}-6^{\prime}\right), 6.92\left(\mathrm{~d}, 1 \mathrm{H}, J=8.4 \mathrm{~Hz}, \mathrm{H}-5^{\prime}\right), 6.88(\mathrm{~d}, 1 \mathrm{H}, J=2.4 \mathrm{~Hz}, \mathrm{H}-8)$, 4.13-4.05 (m, 3H), $3.93(\mathrm{~s}, 3 \mathrm{H}), 3.91(\mathrm{~s}, 3 \mathrm{H}), 2.91(\mathrm{dd}, 1 \mathrm{H}, J=12.0,3.2 \mathrm{~Hz}), 2.70(\mathrm{dd}, 1 \mathrm{H}, J=12.0,7.6$ $\mathrm{Hz}), 2.56(\mathrm{br} \mathrm{s}, 1 \mathrm{H}), 1.48(\mathrm{q}, 2 \mathrm{H}, J=8.0 \mathrm{~Hz}), 1.11(\mathrm{~s}, 6 \mathrm{H}), 0.90(\mathrm{t}, 3 \mathrm{H}, J=8.0 \mathrm{~Hz}) .{ }^{13} \mathrm{C}$ NMR $(100 \mathrm{MHz}$, $\mathrm{CDCl}_{3}$ ): $\delta 175.85$ (C-4), 163.04 (C-7), 157.78 (C-8a), 152.27 (C-2), 149.08 (C-4'), 148.75 (C-3'), 127.89 (C-5), $124.92\left(\mathrm{C}-1^{\prime}\right), 124.58$ (C-3), 121.01 (C-6'), 118.59 (C-4a), 114.83 (C-6), 112.48 (C-2'), $111.13\left(\mathrm{C}-5^{\prime}\right), 100.87$ (C-8), 71.00, 67.98, 55.94 (4'-OMe), 55.92 (3'-OMe), 53.49, 44.05, 33.20, 26.23, 26.18, 8.24. Anal. calcd. for $\mathrm{C}_{26} \mathrm{H}_{33} \mathrm{NO}_{6} \cdot 0.5 \mathrm{H}_{2} \mathrm{O}: \mathrm{C} 68.21, \mathrm{H}$ 7.39, N 3.02; found: C 68.55, H 7.30, N 3.07.

3-(3,4-Dimethoxyphenyl)-7-\{2-hydroxy-3-[(2-phenylpropan-2-yl)amino]propoxy\}-4H-chromen-4-one (6f): Yield 68\%. Mp.: $131-132{ }^{\circ} \mathrm{C} .{ }^{1} \mathrm{H}$ NMR $\left(400 \mathrm{MHz}, \mathrm{CDCl}_{3}\right): \delta 8.18(\mathrm{~d}, 1 \mathrm{H}, J=8.8 \mathrm{~Hz}, \mathrm{H}-5), 7.94(\mathrm{~s}, 1 \mathrm{H}$, H-2), 7.46-7.43 (m, 2H), 7.36-7.32 (m, 2H), 7.25-7.21 (m, 1H), $7.19\left(\mathrm{~d}, 1 \mathrm{H}, J=2.0 \mathrm{~Hz}, \mathrm{H}-2^{\prime}\right), 7.04(\mathrm{dd}$, $\left.1 \mathrm{H}, J=8.0,2.0 \mathrm{~Hz}, \mathrm{H}-6^{\prime}\right), 6.96(\mathrm{dd}, 1 \mathrm{H}, J=9.2,2.4 \mathrm{~Hz}, \mathrm{H}-6), 6.92\left(\mathrm{~d}, 1 \mathrm{H}, J=8.4 \mathrm{~Hz}, \mathrm{H}-5^{\prime}\right), 6.83(\mathrm{~d}, 1 \mathrm{H}$, $J=2.4 \mathrm{~Hz}, \mathrm{H}-8), 4.03-3.96(\mathrm{~m}, 3 \mathrm{H}), 3.92(\mathrm{~s}, 3 \mathrm{H}), 3.91(\mathrm{~s}, 3 \mathrm{H}), 2.65(\mathrm{dd}, 1 \mathrm{H}, J=12.0,3.6 \mathrm{~Hz}), 2.48(\mathrm{dd}, 1 \mathrm{H}$, $J=12.0,7.2 \mathrm{~Hz}), 2.07$ (br s, $1 \mathrm{H}, \mathrm{NH}), 1.51(\mathrm{~s}, 6 \mathrm{H}) .{ }^{13} \mathrm{C} \mathrm{NMR}\left(100 \mathrm{MHz}, \mathrm{CDCl}_{3}\right): \delta 175.85(\mathrm{C}-4), 162.98$ (C-7), 157.73 (C-8a), 152.25 (C-2), 149.01 (C-4'), 148.68 (C-3'), 146.93, 128.30 (2C), 127.72 (C-5), 126.53, 
$125.73(2 \mathrm{C}), 124.88\left(\mathrm{C}-1^{\prime}\right), 124.53$ (C-3), $120.97\left(\mathrm{C}-6^{\prime}\right), 118.50$ (C-4a), 114.80 (C-6), 112.38 (C-2'), 111.05 $\left(\mathrm{C}-5^{\prime}\right), 100.76$ (C-8), 70.98, 68.73, 55.90 (3'-OMe, 4'-OMe), 55.76, 45.14, 29.68, 29.37. Anal. calcd. for $\mathrm{C}_{29} \mathrm{H}_{31} \mathrm{NO}_{6}$ : C 71.15, H 6.38, N 2.86; found: C 71.01, H 6.34, N 2.57.

3-(3,4-Dimethoxyphenyl)-7-\{2-hydroxy-3-[(2-morpholinopropan-2-yl)amino]propoxy\}-4H-chromen-4-one (6g): Yield 78\%. Mp: 108-109 ${ }^{\circ} \mathrm{C} .{ }^{1} \mathrm{H}$ NMR $\left(400 \mathrm{MHz}, \mathrm{CDCl}_{3}\right): \delta 8.19(\mathrm{~d}, 1 \mathrm{H}, J=8.8 \mathrm{~Hz}, \mathrm{H}-5), 7.93(\mathrm{~s}, 1 \mathrm{H}$, H-2), $7.19\left(\mathrm{~d}, 1 \mathrm{H}, J=2.0 \mathrm{~Hz}, \mathrm{H}-2^{\prime}\right), 7.04-6.98\left(\mathrm{~m}, 2 \mathrm{H}, \mathrm{H}-6, \mathrm{H}-6^{\prime}\right), 6.91\left(\mathrm{~d}, 1 \mathrm{H}, J=8.4 \mathrm{~Hz}, \mathrm{H}-5^{\prime}\right), 6.85(\mathrm{~d}$, $1 \mathrm{H}, J=2.4 \mathrm{~Hz}, \mathrm{H}-8), 4.32-4.30(\mathrm{~m}, 1 \mathrm{H}), 4.15-4.07(\mathrm{~m}, 2 \mathrm{H}), 3.92(\mathrm{~s}, 3 \mathrm{H}), 3.91(\mathrm{~s}, 3 \mathrm{H}), 3.78-3.72(\mathrm{~m}, 4 \mathrm{H})$, 3.15-3.11 (m, 1H), 2.91-2.83 (m, 2H), 2.67-2.52 (m, 5H) $1.17(\mathrm{~s}, 3 \mathrm{H}), 1.10(\mathrm{~s}, 3 \mathrm{H}) .{ }^{13} \mathrm{C} \mathrm{NMR}(100 \mathrm{MHz}$, $\mathrm{CDCl}_{3}$ ): $\delta 175.78$ (C-4), 162.79 (C-7), 157.72 (C-8a), 152.29 (C-2), 149.07 (C-4'), $148.72\left(\mathrm{C}-3^{\prime}\right), 127.80$ (C-5), $124.90\left(\mathrm{C}-1^{\prime}\right), 124.49$ (C-3), 121.00 (C-6'), 118.64 (C-4a), 114.72 (C-6), 112.43 (C-2'), $111.10\left(\mathrm{C}-5^{\prime}\right), 100.86$ (C-8), 70.56, 67.33 (2C), 66.54, 56.49, 56.14, 55.93 (4'-OMe), 55.90 (3'-OMe), 52.19, 45.82 (2C), 22.37, 20.81. Anal. calcd. for $\mathrm{C}_{28} \mathrm{H}_{36} \mathrm{~N}_{2} \mathrm{O}_{7} \cdot 0.5 \mathrm{H}_{2} \mathrm{O}$ : C 64.46, H 7.16, N 5.37; found: C 64.26, H 7.18, N 5.20.

3-(3,4-Dimethoxyphenyl)-7-\{3-\{[1-(4-fluorophenyl)-2-methylpropan-2-yl]amino\}-2-hydroxypropoxy\}4H-chromen-4-one (6h): Yield 83\%. Mp: 151-152 ${ }^{\circ} \mathrm{C} .{ }^{1} \mathrm{H}$ NMR $\left(400 \mathrm{MHz}, \mathrm{DMSO}-d_{6}\right): \delta 8.46$ (s, $\left.1 \mathrm{H}, \mathrm{H}-2\right)$, $8.04(\mathrm{~d}, 1 \mathrm{H}, J=8.8 \mathrm{~Hz}, \mathrm{H}-5), 7.23-7.14(\mathrm{~m}, 5 \mathrm{H}), 7.09(\mathrm{dd}, 1 \mathrm{H}, J=8.8,2.4 \mathrm{~Hz}, \mathrm{H}-6), 7.07-7.01(\mathrm{~m}, 3 \mathrm{H})$, $5.10(\mathrm{br} \mathrm{s}, 1 \mathrm{H}), 4.17(\mathrm{dd}, 1 \mathrm{H}, J=10.0,4.0 \mathrm{~Hz}), 4.06(\mathrm{dd}, 1 \mathrm{H}, J=10.0,6.0 \mathrm{~Hz}), 3.89-3.86(\mathrm{~m}, 1 \mathrm{H}), 3.79$ $(\mathrm{s}, 6 \mathrm{H}), 2.77-2.65(\mathrm{~m}, 2 \mathrm{H}), 2.62(\mathrm{~s}, 2 \mathrm{H}), 0.96(\mathrm{~s}, 3 \mathrm{H}), 0.95(\mathrm{~s}, 3 \mathrm{H}) .{ }^{13} \mathrm{C}$ NMR (100 MHz, DMSO- $\left.d_{6}\right): \delta$ $174.63(\mathrm{C}-4), 163.20(\mathrm{C}-7), 160.77(\mathrm{~J}=240.3 \mathrm{~Hz}), 157.36(\mathrm{C}-8 \mathrm{a}), 153.68(\mathrm{C}-2), 148.48\left(\mathrm{C}-4^{\prime}\right), 148.31\left(\mathrm{C}-3^{\prime}\right)$, $134.84(\mathrm{~J}=3.1 \mathrm{~Hz}), 132.06(2 \mathrm{C}, J=7.6 \mathrm{~Hz}), 126.96(\mathrm{C}-5), 124.38\left(\mathrm{C}-1^{\prime}\right), 123.47(\mathrm{C}-3), 121.27\left(\mathrm{C}-6^{\prime}\right), 117.55$ (C-4a), $115.15(\mathrm{C}-6), 114.26(2 \mathrm{C}, J=20.5 \mathrm{~Hz}), 112.76\left(\mathrm{C}-2^{\prime}\right), 111.57\left(\mathrm{C}-5^{\prime}\right), 101.08(\mathrm{C}-8), 71.52,68.87,55.56$ (4'-OMe), 55.55 (3'-OMe), 52.49, 45.37, 44.61, 26.66, 26.58. Anal. calcd. for $\mathrm{C}_{30} \mathrm{H}_{32} \mathrm{FNO}_{6} \cdot 0.2 \mathrm{H}_{2} \mathrm{O}: \mathrm{C}$ 68.61, H 6.22, N 2.67; found: C 68.49, H 6.21, N 2.26.

3-(3,4-Dimethoxyphenyl)-7-\{2-hydroxy-3-\{[(1-morpholinocyclohexyl)methyl]amino\}propoxy\}-4H-chromen4-one (6i): Yield 74\%. Mp: 67-68 ${ }^{\circ} \mathrm{C} .{ }^{1} \mathrm{H}$ NMR $\left(400 \mathrm{MHz}, \mathrm{CDCl}_{3}\right): \delta 8.19(\mathrm{~d}, 1 \mathrm{H}, J=8.8 \mathrm{~Hz}, \mathrm{H}-5), 7.93(\mathrm{~s}$, 1H, H-2), 7.19 (d, 1H, J = 2.0 Hz, H-2'), 7.04-6.99 (m, 2H, H-6, H-6' $), 6.91\left(\mathrm{~d}, 1 \mathrm{H}, J=8.0 \mathrm{~Hz}, \mathrm{H}-5^{\prime}\right), 6.86$ $(\mathrm{d}, 1 \mathrm{H}, J=2.4 \mathrm{~Hz}, \mathrm{H}-8), 4.34-4.32(\mathrm{~m}, 1 \mathrm{H}), 4.15-4.07(\mathrm{~m}, 2 \mathrm{H}), 3.92(\mathrm{~s}, 3 \mathrm{H}), 3.91(\mathrm{~s}, 3 \mathrm{H}), 3.76-3.69(\mathrm{~m}$, $4 \mathrm{H}), 3.14-3.05(\mathrm{~m}, 2 \mathrm{H}), 2.84(\mathrm{dd}, 1 \mathrm{H}, J=12.0,8.8 \mathrm{~Hz}), 2.69-2.57(\mathrm{~m}, 5 \mathrm{H}), 1.69-1.19(\mathrm{~m}, 12 \mathrm{H}) .{ }^{13} \mathrm{C}$ NMR $\left(100 \mathrm{MHz}, \mathrm{CDCl}_{3}\right): \delta 175.78$ (C-4), 162.80 (C-7), 157.72 (C-8a), 152.28 (C-2), $149.07\left(\mathrm{C}-4^{\prime}\right), 148.73\left(\mathrm{C}-3^{\prime}\right)$, 127.81 (C-5), $124.90\left(\mathrm{C}-1^{\prime}\right), 124.49$ (C-3), $121.00\left(\mathrm{C}-6^{\prime}\right), 118.64$ (C-4a) 114.72 (C-6), $112.44\left(\mathrm{C}-2^{\prime}\right), 111.11$ (C-5'), 100.87 (C-8), 70.60, 67.75 (2C), 66.52, 58.22, 55.92 (4'-OMe), 55.90 (3'-OMe), 52.33, 50.01, 45.41 (2C), 29.99, 29.63, 25.77, 22.07, 21.98. Anal. calcd. for $\mathrm{C}_{31} \mathrm{H}_{40} \mathrm{~N}_{2} \mathrm{O}_{7} \cdot 2.6 \mathrm{H}_{2} \mathrm{O}: \mathrm{C}$ 62.10, H 7.60, N 4.67; found: C 61.88, H 7.20, N 4.47.

\subsubsection{Cytotoxicity and Antiviral Activity Assays}

Compounds

Compounds were dissolved in DMSO at $10 \mathrm{mM}$ and then diluted in culture medium.

Cell

Ava5 cells, an engineered HCV subgenomic replicon cell line, were cultured in Dulbecco's modified Eagle's medium (DMEM) with 10\% heat-inactivated fetal bovine serum, $1 \%$ antibiotic-antimycotic, and $1 \%$ non-essential amino acids. Ava5 cells were maintained in DMEM with $1 \mathrm{mg} \mathrm{mL}^{-1} \mathrm{G} 418$ to maintain the stable expression of replicon.

Cytotoxicity Assays

For cytotoxicity tests, run in parallel with antiviral assays, plates at an initial density of $\left(5 \times 10^{3}\right.$ cells/well $)$ were treated with or without serial dilutions of test compounds. Cell viability was determined after $72 \mathrm{~h}$ at $37{ }^{\circ} \mathrm{C}$ in a humidified $\mathrm{CO}_{2}(5 \%)$ atmosphere by the (2,3-bis[2-methyloxy-4-nitro-5-sulfophenyl]-2H-tetrazolium-5-carboxanilide) (XTT) method [24]. 
Transfection and Luciferase Activity Assay

Ava5 cells were transfected with the HO-1 promoter-driven luciferase plasmid, pHO-1-Luc, using the T-pro ${ }^{\mathrm{TM}}$ transfection reagent (Ji-Feng Biotechnology Co., Ltd., Taipei, Taiwan) according to the manufacturer's instructions. The transfected cells were treated with compounds at various concentrations for 3 days. Each transfection complex contains $0.1 \mu \mathrm{g}$ pSEAP, a secreted alkaline phosphatase (SEAP) expression vector, for normalization luciferase activity serving as a transfection control. The luciferase activity assay was performed using the Bright-Glo Luciferase assay system (Promega) (Madison, WI, USA) according to the manufacturer's instructions.

Immunoblot Analysis

Ava5 cells were seeded in 24-well plates at a density of $5 \times 10^{4}$ cells per well overnight and treated with indicated reagent at proper concentrations for 3 days. Cells were washed with cold phosphate buffer saline (PBS) and lysed by radioimmunoprecipitation assay (RIPA) lysis buffer (50 mM Tris-HCl, pH 7.5, 150 mM NaCl, $1 \%$ Nonidet P-40, 2 mM EDTA, 1 mM EGTA, 1 mM NaVO , $10 \mathrm{mM} \mathrm{NaF}, 1 \mathrm{mM}$ DTT, $1 \mathrm{mM}$ PMSF, $25 \mu \mathrm{g} / \mathrm{mL}$ aprotinin, and $25 \mu \mathrm{g} / \mathrm{mL}$ leupeptin) and stored at $-20{ }^{\circ} \mathrm{C}$. The protein concentration was determined by the Bradford method. Ten $\mu \mathrm{g}$ protein were separated by $10 \%$ SDS-PAGE and transferred onto a polyvinylidene difluorid (PVDF) membrane. The membrane was blocked with $5 \%$ non-fat dried milk and incubated with specific antibodies against NS5B (1:5000; Abcam Cambridge, MA, USA), glyceraldehyde-3-phosphate dehydrogenase (GAPDH) and anti-HO-1 (1:3000, Abcam Cambridge, MA, USA). Antibodies were diluted in 5\% milk containing Tris-buffered saline (TBS) and 0.5\% Tween. The blotting signal was developed using an ECL detection kit (PerkinElmer, Norwalk, CT, USA) and was counted by the software Quantity One (Bio-Rad, Foster, CA, USA).

\section{Conclusions}

We have synthesized and evaluated 3-amino-2-hydroxypropoxyisoflavone derivatives for their inhibitory activities of anti-HCV replication. These compounds exhibited better $\mathrm{EC}_{50}$ and $\mathrm{SI}$ values than ribavirin upon the antiviral experiment. Among them, 7-\{3-[(3,4-dimethoxyphenethyl)amino]-2-hydroxypropoxy\}-3-(3,4-dimethoxyphenyl)-4H-chromen-4-one (6b) exhibited the most potent activity against HCV replication. By the determination of antiviral mechanism, the results indicated that compounds $\mathbf{6 b}, \mathbf{6 e}, \mathbf{6} \mathbf{h}$, and $\mathbf{6 i}$ reduced HCV replication through Nrf2-mediated HO-1 induction. Further studies on the structural optimization are ongoing.

Supplementary Materials: The supplementary materials are available online.

Author Contributions: J.-C.L. participated in the biological activity, the interpretation of the results and in manuscript writing; C.-K.L. and C.-K.T. participated in the biological activity; Y.-L.C. and C.-C.T. participated in synthesis; C.-H.T. participated in synthesis, purification and characterization of the chemical compounds and suggested the research idea, participated in the interpretation of the results and in manuscript writing.

Funding: Financial support of this work by the Minister of Science and Technology of the Republic of China (MOST 107-2320-B-037-015, MOST 106-2320-B-037-015, MOST 105-2320-B-037-011) and Kaohsiung Medical University (KMU-TP105E16, 105KMUOR02) are gratefully acknowledged.

Acknowledgments: Authors were thankful to the Center for Research Resources and Development at Kaohsiung Medical University for the instrumentation and equipment support.

Conflicts of Interest: The authors declare no conflict of interest.

\section{References}

1. Gravitz, L. Introduction: A smouldering public-health crisis. Nature 2011, 474, 2-4. [CrossRef] [PubMed]

2. Mohd Hanafiah, K.; Groeger, J.; Flaxman, A.; Wiersma, S. Global epidemiology of hepatitis C virus infection: New estimates of age-specific antibody to HCV seroprevalence. Hepatology 2013, 57, 1333-1342. [CrossRef] [PubMed] 
3. Mohamed, A.A.; Elbedewy, T.A.; El-Serafy, M.; El-Toukhy, N.; Ahmed, W.; Ali El Din, Z. Hepatitis C virus: A global view. World J. Hepatol. 2015, 7, 2676-2680. [CrossRef] [PubMed]

4. Abdelwahab, K.S.; Ahmed Said, Z.N. Status of hepatitis C virus vaccination: Recent update. World J. Gastroenterol. 2016, 22, 862-873. [CrossRef] [PubMed]

5. Petta, S.; Craxì, A. Current and future HCV therapy: Do we still need other anti-HCV drugs? Liver Int. 2015, 35 (Suppl. S1), 4-10. [CrossRef] [PubMed]

6. Gottwein, J.M.; Pham, L.V.; Mikkelsen, L.S.; Ghanem, L.; Ramirez, S.; Scheel, T.K.H.; Carlsen, T.H.R.; Bukh, J. Efficacy of NS5A inhibitors against hepatitis C virus genotypes 1-7 and escape variants. Gastroenterology. 2018, 154, 1435-1448. [CrossRef] [PubMed]

7. Dousson, C.B. Current and future use of nucleo(s)tide prodrugs in the treatment of hepatitis $\mathrm{C}$ virus infection. Antivir. Chem. Chemother. 2018, 26. [CrossRef] [PubMed]

8. Pinho, P.; Kalayanov, G.; Westerlind, H.; Rosenquist, Å.; Wähling, H.; Sund, C.; Almeida, M.; Ayesa, S.; Tejbrant, J.; Targett-Adams, P.; et al. Discovery of $\beta$-d-2'-deoxy-2'-dichlorouridine nucleotide prodrugs as potent inhibitors of hepatitis C virus replication. Bioorg. Med. Chem. Lett. 2017, 27, 3468-3471. [CrossRef] [PubMed]

9. Liu, B.; Gai, K.; Qin, H.; Liu, X.; Cao, Y.; Lu, Q.; Lu, D.; Chen, D.; Shen, H.; Song, W.; et al. Design, synthesis and identification of silicon-containing HCV NS5A inhibitors with pan-genotype activity. Eur. J. Med. Chem. 2018, 148, 95-105. [CrossRef] [PubMed]

10. Zhang, X.; Lv, X.Q.; Tang, S.; Mei, L.; Li, Y.H.; Zhang, J.P.; Jiang, J.D.; Peng, Z.G.; Song, D.Q. Discovery and evolution of aloperine derivatives as a new family of HCV inhibitors with novel mechanism. Eur. J. Med. Chem. 2018, 143, 1053-1065. [CrossRef] [PubMed]

11. Andreev, I.A.; Manvar, D.; Barreca, M.L.; Belov, D.S.; Basu, A.; Sweeney, N.L.; Ratmanova, N.K.; Lukyanenko, E.; Manfroni, G.; Cecchetti, V.; et al. Discovery of the 2-phenyl-4,5,6,7-Tetrahydro-1H-indole as a novel anti-hepatitis C virus targeting scaffold. Eur. J. Med. Chem. 2015, 96, 250-258. [CrossRef] [PubMed]

12. Kaushik-Basu, N.; Ratmanova, N.K.; Manvar, D.; Belov, D.S.; Cevik, O.; Basu, A.; Yerukhimovich, M.M.; Lukyanenko, E.R.; Andreev, I.A.; Belov, G.M.; et al. Bicyclic octahydrocyclohepta[b]pyrrol-4(1H)one derivatives as novel selective anti-hepatitis C virus agents. Eur. J. Med. Chem. 2016, 122, 319-325. [CrossRef] [PubMed]

13. Zhong, D.; Liu, M.; Cao, Y.; Zhu, Y.; Bian, S.; Zhou, J.; Wu, F.; Ryu, K.C.; Zhou, L.; Ye, D. Discovery of metal ions chelator quercetin derivatives with potent anti-HCV activities. Molecules 2015, 20, 6978-6999. [CrossRef] [PubMed]

14. Tseng, C.H.; Lin, C.K.; Chen, Y.L.; Tseng, C.K.; Lee, J.Y.; Lee, J.C. Discovery of naphtho[1,2-d]oxazole derivatives as potential anti-HCV agents through inducing heme oxygenase-1 expression. Eur. J. Med. Chem. 2018, 143, 970-982. [CrossRef] [PubMed]

15. Su, Q.; Krai, P.; Goetz, M.; Cassera, M.B.; Kingston, D.G. Antiplasmodial isoflavones and pterocarpans from apoplanesia paniculata. Planta Med. 2015, 81, 1128-1132. [PubMed]

16. Zhang, Y.; Zhong, H.; Lv, Z.; Zhang, M.; Zhang, T.; Li, Q.; Li, K. Anti-hepatitis B virus and anti-cancer activities of novel isoflavone analogs. Eur. J. Med. Chem. 2013, 62, 158-167. [CrossRef] [PubMed]

17. Jantaratnotai, N.; Utaisincharoen, P.; Sanvarinda, P.; Thampithak, A.; Sanvarinda, Y. Phytoestrogens mediated anti-inflammatory effect through suppression of IRF-1 and PSTAT1 expressions in lipopolysaccharide activated microglia. Int. Immunopharmacol. 2013, 17, 483-488. [CrossRef] [PubMed]

18. Huang, P.H.; Tseng, C.H.; Lin, C.Y.; Lee, C.W.; Yen, F.L. Preparation, characterizations and anti-pollutant activity of 7,3', $4^{\prime}$-trihydroxyisoflavone nanoparticles in particulate matter-induced HaCaT keratinocytes. Int. J. Nanomed. 2018, 13, 3279-3293. [CrossRef] [PubMed]

19. Tseng, C.H.; Chen, Y.L.; Lu, C.M.; Wang, C.K.; Tsai, Y.T.; Lin, R.W.; Chen, C.F.; Chang, Y.F.; Wang, G.J.; Ho, M.L.; et al. Synthesis and anti-osteoporotic evaluation of certain 3-amino-2-hydroxypropoxy isoflavone derivatives. Eur. J. Med. Chem. 2009, 44, 3621-3626. [CrossRef] [PubMed]

20. Chen, W.C.; Wang, S.Y.; Chiu, C.C.; Tseng, C.K.; Lin, C.K.; Wang, H.C.; Lee, J.C. Lucidone suppresses hepatitis $C$ virus replication by Nrf2-mediated heme oxygenase-1 induction. Antimicrob. Agents Chemother. 2013, 57, 1180-1191. [CrossRef] [PubMed]

21. Reichard, J.F.; Motz, G.T.; Puga, A. Heme oxygenase-1 induction by NRF2 requires inactivation of the transcriptional repressor BACH1. Nucleic Acids Res. 2007, 35, 7074-7086. [CrossRef] [PubMed] 
22. Magesh, S.; Chen, Y.; Hu, L. Small molecule modulators of Keap1-Nrf2-ARE pathway as potential preventive and therapeutic agents. Med. Res. Rev. 2012, 32, 687-726. [CrossRef] [PubMed]

23. Tkachev, V.O.; Menshchikova, E.B.; Zenkov, N.K. Mechanism of the Nrf2/Keap1/ARE signaling system. Biochemistry 2011, 76, 407-422. [CrossRef] [PubMed]

24. Roehm, N.W.; Rodgers, G.H.; Hatfield, S.M.; Glasebrook, A.L. An improved colorimetric assay for cell proliferation and viability utilizing the tetrazolium salt XTT. J. Immunol. Methods 1991, 142, 257-265. [CrossRef]

Sample Availability: Samples of the compounds reported herein are available from the authors.

(C) 2018 by the authors. Licensee MDPI, Basel, Switzerland. This article is an open access article distributed under the terms and conditions of the Creative Commons Attribution (CC BY) license (http://creativecommons.org/licenses/by/4.0/). 